\title{
Siguiendo el guion, pero guardando el decoro: cuchilladas y libreas en la Tercera Celestina
}

\author{
Rosa Navarro Durán \\ Universitat de Barcelona
}

\section{RESUMEN}

La Tercera parte de la tragicomedia de Celestina se presenta como continuación de la Segunda comedia de Celestina de Feliciano de Silva; Gaspar Gómez tiene, por tanto, poca libertad al aceptar el guion de la comedia que va a terminar; pero encontrará un camino distinto devolviendo el decoro a los personajes. Lo hará haciendo que los rufianes den golpes y cuchilladas a Celestina y que ella sea castigada como alcahueta públicamente, aunque se irá a la tumba por su propio pie. Y además el escritor dará pompa, comedimiento y gran generosidad al rico y noble caballero Felides, que se desposará en ceremonia religiosa con su amada Polandria, de igual condición. El objetivo del escritor es restaurar el orden social que su modelo dejó trastocado: el mundo de los rufianes, prostitutas y alcahueta se separa por completo del de los señores, con su exhibición pública de honra, riqueza y poder.

Palabras Clave: Celestina, decoro, casamentera, rufianes, cortesanos.

Keeping to the script but observing decorum: knife slashes and liveries in Tercera Celestina

\begin{abstract}
The Tercera parte de la tragicomedia de Celestina is presented as a continuation of Feliciano de Silva's Segunda comedia de Celestina, therefore Gaspar Gómez has limited creative freedom as he accepted the script of the play which he is going to finish. Nevertheless, he finds a different path for the story by giving decorum back to the characters. The author does it in this manner: the ruffians hit and slash Celestina and she is punished as a bawd in public, but she will die on her own. Furthermore, Gaspar Gómez gives splendour, courtesy and great generosity to the rich and noble gentleman Felides, who will marry her beloved Polandria, a lady of equal social standing, in a religious ceremony. The author's aim is to restore the social order which his predecessor disrupted. In Tercera Celestina, the world of ruffians, prostitutes and the bawd is absolutely separated from that of the gentlemen and ladies, with their public exhibition of honour, wealth and power.
\end{abstract}

KeYwords: Celestina, decorum, matchmaker, ruffians, courtiers. 
La Tercera parte de la tragicomedia de Celestina se ofrece como continuación de la Segunda comedia de Celestina de Feliciano de Silva: "Va prosiguiendo en los amores de Felides y Polandria, conclúyense sus deseados desposorios, y la muerte y desdichado fin que ella hobo» (Gómez 2016: 353), y además con la muerte anunciada de Celestina se justifica la vuelta al título de "tragicomedia» de la obra origen del género en vez de mantener el de "comedia» que tiene la Segunda. Gaspar Gómez, «natural de la muy insigne ciudad de Toledo", no solo le toma a Feliciano de Silva a sus personajes, sino que le dirige la obra y convierte su prólogo en carta no al lector, sino al escritor; bien es cierto que este con su continuación de La Celestina "resucitando» a su personaje —es decir, decidiendo que su muerte fuera solo apariencia - daba licencia para que cualquier escritor hiciese lo mismo con su obra, y Gaspar Gómez siguió su camino. La diferencia es que él la escribe en vida de Feliciano de Silva y, no sabemos si para captar su benevolencia, se la dirige y lo alaba con entusiasmo.

Precisamente el estilo del personaje de Felides en su primer parlamento en la Segunda, lleno de figuras etimológicas - derivaciones, políptotosle sirve de pie retórico a Gómez para alabar a Silva. No está mal recordarlo porque se convertiría además en motivo de burla desde Diego Hurtado de Mendoza y Lucas Gracián Dantisco a Miguel de Cervantes:
¡Ay de ti, Felides!, que ni la grandeza de tu corazón te pone el esfuerzo, ni la sabiduría consejo, ni la riqueza es- peranza para esperar, en la razón que para amar tuviste, la que en tal razón se niega para esperar el remedio, por el merecimiento, valor y hermosura de mi señora; por- que cuanto por una parte pide la razón de amarse, por la otra niega, en la razón de tal servicio, la poca que para esperar remedio hay. (Silva 2016: 7)

Aunque la mofa se asentó sobre todo en el final de ese mismo parlamento: « $\mathrm{Oh}$, amor, que no hay razón en que tu sinrazón no tenga mayor razón en sus contrarios! Y pues tú me niegas con tus sinrazones lo que en razón de tus leyes prometes» (Silva 2016: 8).

Con esta guía no hay más que empezar a leer la dedicatoria de Gaspar Gómez para ver repetidas estas figuras retóricas del estilo cancioneril:

Como en los tiempos antiguos no era digno de memoria sino el que, ejercitando su vida en algún notable ejercicio, después de sus días la dejaba, quise forzar a mis fuerzas a que, siendo favorecidas con el favor que de vuestra merced espero, tomasen ocupación en se ocupar algunos ratos en poner en obra a hacer esta obrecilla. (Gómez 2016: 355) 
Y seguirá hasta el final, en donde ruega al lector que "esta leyere» que lea primero la Segunda, "que es antes que esta». Como bien dijo Heugas:

Le prologue de la Tercera Celestina est le seul à ne comporter aucun apport doctrinal. Gaspar Gómez place son oeuvre sous la protection de Feliciano de Silva dont il fait un éloge outrancier après des déclarations de modestie excessives. Dans ce prologue, il loue le style de Feliciano de Silva "la langue subtile et élégante» qu'il essaie lourdement d'imiter à travers des «jeux de vocables». (Heugas 1973: 547)

Es tanta la repetición de los mismos recursos retóricos que da que pensar, porque no puede ser tan solo la muestra de la inhabilidad de Gómez, como dice Heugas, y además el retórico primer parlamento de su Felides no está escrito a su semejanza, aunque acumule también figuras y referencias cultas.

El estudioso señala al final de su espléndido estudio «la non-liberté dans laquelle une tradition enfermait» a los imitadores de La Celestina, que les obligaba a encontrar su propio camino, es decir a «retrouver les voies de leur liberté créatrice» (Heugas 1973: 586). La libertad de Gaspar Gómez no podía ser menor puesto que, si anunciaba su Tercera Celestina como continuación de la Segunda, tenía que seguir su guion y cerrar lo que en ella Feliciano de Silva había dejado abierto. ¿Y dónde va a encontrar un camino su libertad creadora? Pues precisamente en la enmienda, en la soterrada crítica a su modelo: ¿hay que leer en esa dirección su dedicatoria?, ¿quiso hacer una exhibición del estilo farragoso que suele caracterizar - aunque no siempre - al personaje de Felides? Como voy a demostrar, Gómez rectificará a Silva en la creación de su protagonista y le devolverá el decoro de su condición de noble y rico caballero.

Voy primero a señalar cómo escoge otros modelos para dar inicio a su obra, luego a indicar cómo sigue el guion que Feliciano de Silva le ofrece $y$, por último, mostrar que, al introducir modificaciones significativas en él, va a restaurar el orden social que su modelo dejó trastocado.

\section{De la Comedia Thebaida a la Aquilana y la Vidriana}

La Tercera parte de la tragicomedia de Celestina se inicia con un largo monólogo de Felides, cuyo final escucha y comenta un asombrado Sigeril; su asunto lo resume bien el argumento inicial: «Felides recuerda y empieza a razonar como que halla ser imposible haber estado la noche pasada con su señora Polandria, y afirmándolo por sueño, llama a Sigeril para que le diga la certenidad de aquella duda que tiene, en lo cual pasan muchas razones» (Gómez 2016: 357). 
El caballero, que se ha despertado tarde tras la noche de placer vivida en la última escena de la Segunda Celestina — habla del «deleite de su sueño»-, llama a Sigeril, que está junto a él pero retrasa su presencia, y este le va a recordar a su señor lo distintas que fueron sus noches: "Y es que ya todos sabemos que el que camina de día, le es convenible dormir la noche; y por el consiguiente, el que de noche lo usa, de día ha de descansar. Y esto no lo digo por mí, pues no hay razón para ello» (Gómez 2016: 360).

Felides se acuerda solo de lo que pasó la primera de las tres noches y cree que es lo vivido la noche pasada y que lo demás lo ha soñado: "Ya sabes como anoche fuimos a ver a mi señora Polandria, y la hablé por ser mi ventura tan dichosa; $y$ por no haber disposición, aun las manos no hubo lugar de le besar» (Gómez 2016: 361). Sigeril le contará la verdad de lo sucedido, y así el lector tiene un resumen de las tres citas nocturnas en el jardín de Felides y Polandria acaecidas en el texto de la obra de Feliciano de Silva. Como el caballero no acaba de creérselo, mientras se hace la hora de comer, manda a su paje a casa de Polandria diciéndole: "Quizás la verás y sabremos la certinidad de lo pasado» (Gómez 2016: 363).

Sigeril no llegará a ir a casa de la dama porque se topa por la calle con Pandulfo, y decide luego regresar y mentirle a su señor anunciándole una nueva cita a las doce de la noche acompañada con música. Por una parte, con el encuentro de los dos, se resume lo acaecido antes; pero, por otra, el lector se da cuenta de la degradación del mundo de los criados: el rufián quiere explotar a Quincia convirtiéndola en su iza y llevándosela al publique de Valencia, y el fiel Sigeril va a mentir a su amo sin rebozo alguno.

Con la imagen de un Felides completamente alienado Gaspar Gómez enlaza su obra con otra imitación de La Celestina: con la Comedia Thebaida porque comienza con el parlamento de Berintho de igual forma. Ni se da cuenta de que no está solo, sino con Menedemo y Galterio, a los que antes había llamado y contado el proceso de sus amores, ni tan siquiera se acuerda de quién es Franquila, la mensajera de sus amores con Cantaflua, cuando ella ha ido a verlo muchas veces. Su alienación es absoluta, como dice Aminthas: "Cierto es lástima de un hombre que así, procurándolo él con sus propias manos, ha quesido enajenarse. $Y$ en verdad que ninguno he visto yo tan apasionado de letargia que tan olvidado esté de sí mesmo» (Thebaida 1968: 15). Felides no llega a tanto, por supuesto, porque solo cree que la vida es sueño, o, mejor dicho, que lo vivido ha sido solo soñado.

Heugas dedica un apartado a la alienación del héroe y señala cómo Calisto confunde el día con la noche en el acto VIII (1973: 430-438); luego enlazará este asunto con la prodigalidad del caballero, que, aunque también está presente en la Tercera Celestina, tiene en la obra otra intención. En el acto XIII Calisto se despierta tras la relación amorosa con Melibea en el huerto la noche anterior y en un monólogo recuerda "el azucarado rato» y se pregunta sobre la verdad de lo vivido: " $\mathrm{O}$ h dichoso y bienandante Calisto, si verdad es que no ha sido sueño lo pasado! ¿Soñelo o no? ¿Fue 
fantaseado o pasó en verdad? Pues no estuve solo; mis criados me acompañaron. Dos eran; si ellos dicen que pasó en verdad, creerlo he según derecho» (Rojas, 2000: 263-264); pero sus criados ya no podrán confirmarle lo que él sabe muy bien porque están muertos. La duda era solo retórica ${ }^{1}$ porque al final del acto dice: "Mucho había anoche alcanzado», y enseguida pensará en Sosia y en Tristanico como compañía suya para la próxima cita nocturna olvidando ya el trágico final de sus otros dos criados.

Es el hecho de que la comedia se inicie con el caballero despertando en la cama olvidado de la realidad, totalmente alienado, lo que indica la imitación de la Thebaida por parte de Gaspar Gómez y su voluntad de hacerlo manifiesto; en ambos casos la escena roza la parodia con la exageración del total olvido del protagonista.

Enseguida —en el acto segundo- Gaspar Gómez se apartará de nuevo del camino para imitar otra comedia, pero en este caso será la Aquilana de Torres $\mathrm{Naharro}^{2}$. No es difícil llegar a esa lectura del escritor, porque él mismo la declara al poner en boca de Sigeril al comienzo del acto segundo, comentando cómo se burló de su alienado señor, la mención de Faceto, el criado de Aquilano: «Bien mirado, yo creo que ni Pármeno y Sempronio tenían tanta razón de hacer burla de Calisto, ni menos Faceto de Aquilano, cuando les vían desbaratar, como yo he tenido hoy de hacerla del señor mi amo» (Gómez 2016: 364).

Pero no será Faceto, sino Galterio ${ }^{3}$ y Dandario, dos hortelanos que inician la jornada segunda, los que le sirven de modelo a Gaspar Gómez para el acto tercero; no hablan como Filinides, el pastor de la Segunda Celestina, sino como rústicos, y son ellos los que tienen al cuidado el huerto del rey, el padre de Felicina. Galterio no sabe por dónde empezar a trabajary Dandario le sugiere regar «el azucena, / los jazmines y el rosal», y les añade "la berenjena, / los garbanzos y el habal» (Torres Naharro 1994: 552). Preferirá Galterio regar primero «las coles y las cebollas», y luego Dandario le propone hacerlo a las higueras, aunque su compañero zanja la cuestión diciendo que es mejor regar los gaznates. Dandario le dice que sería mejor cavar un rato "mientras Febo no se llega», y en la réplica de Galterio aparece ya el descubrimiento que hace: «mas digo, daca, miremos: / ¿de quién son estas pisadas?». Y cuando le pregunta Dandario "cuáles», contestará: «Mira cuántas y qué tales: / hoy quedamos deshonrados».

1.- Como también es expresión del gozo vivido, tan inmenso que parece soñado, en boca de Euríalo cuando tiene en brazos a su amada Lucrecia en la Historia de dos amantes: "Oh, mi ánima, téngote o sueño?, ¿es verdadero este deleite o estó fuera de sentido? No sueño, en verdad, cierto es lo que se trata» (Piccolomini 1907: 52).

2.- Ya Feliciano de Silva había imitado dos pasajes de comedias de Torres Naharro, de la Calamita y de la Aquilana: de esta última viene la interpretación errónea que hace Faceto de lo escrito en la carta que Felicina escribe a Aquilano (Navarro Durán 2018: 386-387).

3.- Nombre que el autor de la Thebaida pone al mozo de espuelas y rufián, el personaje más destacado de la comedia. 
Las siguientes réplicas no dan lugar a dudas:

DANDARIO: ¿Qué diabros de zagales han sido hoy tan ahotados que han entrado onde bien han negociado, pues con las vidas volvieron?

Galterio: Dome a Dios, qu' estó espantado pensando cómo subieron.

DANDARIO: ¡Y escalaron! (Torres Naharro 1994: 652-653)

Quien había escalado había sido Aquilano para hablar con Felicina, con la que volverá a encontrarse la noche siguiente; pero ella se marchará por miedo a ser oída, y quedará amortecido bajo un ciprés y cara al manzano el desesperado enamorado, al que descubrirán los hortelanos, espantados al oír lamentos que creen de alma en pena.

En la Tercera Celestina, como dice el argumento del auto III: «El hortolano de Paltrana, llamado Penuncio, anda por el vergel excavando la hortaliza y platicando consigo de ver por allí pisadas. Halla entre las yerbas un tocado de Polandria, y pareciéndole mal, determina mostrarle a Paltrana» (Gómez 2016: 373); antes va enumerando los cultivos del vergel: albahacas, claveles, regados con el rocío de la madrugada, y se queja de tener que regarlos todas las tardes pues solo se pasea por allí su ama a la puesta del sol, hasta que descubre los destrozos:

Mas, ¿qué bellaquería es esta que todo este perejil está hollado? ¡Y aquellas lechugas, no me parece sino que diez caballos las han pisado! [...] ¡Ojo, ojo!, iy cuál está! ¡Aquella pared de los jazmines toda derribada! ¡No sé qué le haga, que yo con llave dejé la puerta y cerrada la hallo! ¿Qué diablos es aquello blanco que está cabo aquel naranjo? ¡Juro a san Pedro, que es este tocado de la señora Polandria! (Gómez 2016: 374)

Llegará Poncia a coger flores, oirá murmurar a Penuncio y verá que tiene en la mano el tocado de su señora. Decide hablarle para ver si se ha dado cuenta de lo sucedido, y comprobará que sí porque le dice Penuncio: «¿Qué más queréis?, jsino que esta noche entrastes aquí cuando todos dormían y me habéis parado el vergel cual le vees!»; añade además la razón de ello ante el argumento de la muchacha de por qué iban a ir de noche si podían hacerlo de día: «¿Por dicha meteréis a ojos vistas a vuestros amigos en vuestro aposento como esta noche habéis hecho?» (Gómez 2016: 375). Y no solo le reta a negar que el tocado es de Polandria, sino que le enseña las pisadas de hombre junto a las de mujer; empezarán luego los dos un debate humanístico en vituperio y en defensa de la mujer con continuas referencias a personajes mitológicos e históricos. Gaspar Gómez sigue el mismo camino que Silva al alzar a Poncia a tal lugar, y el del autor de la Thebaida, que hace que rufianes y prostitutas 
tengan el mismo conocimiento humanístico que los señores ${ }^{4}$. Canet subraya la gran cantidad de digresiones de la comedia «que amplifican enormemente la débil intriga: debates sobre el amor, causas y efectos; sobre la voluntad, fortuna y hados; sobre las virtudes y vicios; sobre la bondad o maldad de las mujeres» (1993: 54). Junto a la comedia Aquilana de Torres Naharro, aparece, pues, de nuevo el modelo de la Thebaida en esa conversación tan culta entre el hortelano Penuncio y Poncia, la doncella que ya había puesto de manifiesto su sabiduría humanística en la Segunda Celestina; que el hortelano hable de Elena, "mujer del rey Menalao", de Clitemnestra o de Pasife y Faustina en su invectiva contra las mujeres pertenece a las convenciones de la comedia humanística.

Poco después (auto V) el escritor toledano prolongará la presencia de un personaje de Silva con su habla especial: la esclava mora, la negra Boruga, que habrá estado escuchando la conversación entre Poncia y su señora Polandria, en la que le contaba lo sucedido en el vergel con el hortelano. La doncella resume y encarece perfectamente la disputa humanística que sostuvieron, y en su asombro podría verse la crítica del propio escritor a esa "sabiduría» del hortelano, que él tomó de los personajes de la Thebaida.

Que jsi de contarte hubiese lo que Penuncio me predicó acerca de la materia, espantarte hías!; que por cierto si diez años estudiara la santa Teología, y otros veinte usara acompañarse con grandes filósofos, no podía mejor fundados traer enjemplos de mujeres que han seguido el mundo desde Adam hasta nuestros tiempos. (Gómez 2016: 395)

De pronto a Poncia le parece que hay alguien y, en efecto, es Boruga ${ }^{5}$, que ha escuchado y además reprueba lo oído y amenaza con contárselo a su señora: "Anxí por tu vira, puex no yamar mujer a mí xi aquí máx paro xin decir xeñora coxa paxar no xufridera, ique caxtigo no tardar voxotras! (Gómez 2016: 396). Poncia acallará esa voz prometiéndole servir de intermediaria entre ella y Buzarco y regalándole una cofia; ya no volverá a aparecer Boruga en la comedia. Pero Gaspar Gómez no renuncia a las jergas literarias y para ello va a introducir a otro personaje: al vizcaíno Perucho, mozo de espuelas de Felides. La marcha de Pandulfo llevándose a Quincia deja ese hueco que aprovecha el escritor para trazar una pequeña senda propia, aunque también imitando otros modelos.

Cuenta Sigeril a Felides: "a Celestina hallé herida en una pierna de una gentil cuchillada que Pandulfo la dio porque no le prestó la desventurada

4.- Hace algo parecido Feliciano de Silva en la Segunda porque no solo demuestran sus conocimientos Poncia y Polandria, sino también la propia Celestina, que cita a Régulo, Cipión, Demóstenes, Séneca, etc.

5.- Para el paréntesis que Zambrán y Boruga abren con su habla de negros en el texto de Silva, y sus antecedentes, véase Navarro Durán (2018: 384-389). 
unos dineros» (Gómez 2016: 467), y necesita, por tanto, una mula y un mozo para que los acompañe a él y a la vieja a casa de su señor; para tal menester va a aparecer en el acto XVI de la tragicomedia Perucho quejándose de la vida que lleva y cantando una canción en vascuence. Así comienza su monólogo: «¡Oh, Perucho, Perucho, cuán mala vida hallada le tienes! Linaje hidalgo, tú caballo limpias. No faltará de comer un pedazo oguia sin que trabajo tanto le tengas» (Gómez 2016: 469). ¿A qué modelos pudo recurrir el escritor?

Torres Naharro le ofrece de nuevo a un vizcaíno: en la jornada segunda de la comedia Tinellaria, como comensales en el tinelo del cardenal de Bacano, aparecen como siervos un Portugués, un Tudesco y un Vizcaíno, cada uno de ellos hablando en su lengua al igual que Petiján, otro siervo, que habla francés, Fabio, en italiano, y Miquel, en catalán. Así dice el Vizcaíno:

$$
\begin{aligned}
& \text { Digo, hao, } \\
& \text { yo criado estás en nao, } \\
& \text { bizcanio eres, por cierto; } \\
& \text { mas juro a Dios que Bilbao } \\
& \text { la tiene mucho buen puerto. }
\end{aligned}
$$

(Torres Naharro 1994: 360)

Tendrá tres breves réplicas más y reaparecerá todavía más fugazmente en la jornada tercera diciendo a Escalco ${ }^{6}$, el superintendente del tinelo: "Señora, dicho as patrón / que lo mandas dar el parte», y como él se niega replicando que no está ahí «por mozo de cada cual», el Vizcaíno sentencia: «No has quesido» (Torres Naharro 1994: 379). En Tinellaria está, pues, con su jerga literaria de vizcaíno, es un siervo y come en el tinelo del cardenal.

Es otra la obra que tiene un personaje de vizcaíno con mucho más papel, que es hortelano y también se llama Perucho: la comedia Vidriana de Jaime de Huete; ya Barrick señaló esa concordancia: «There are many points of similarity between the Tercera Celestina and Jaime de Güete's Comedia Vidriana. Both works have a vizcaino named Perucho, though in Güete's work he is a gardener much like Penuncio in the Tercera Celestina» (1973: 60).

En la jornada cuarta, Lepidano, el padre de Leriana, la protagonista, invita a su mujer, Modesta, a bajar al jardín por la escalera de caracol, aprovechando el frescor de la mañana, porque quiere hablar con ella. El gusto por ver las flores se le trueca en disgusto al comprobar lo mal cuidado que está el huerto: «aqueste nuestro hortelano / tiene cierto / muy mal curado este huerto» (Huete 202: 182). Va a plantear a su mujer la conveniencia de que su única hija se case, pero tienen que interrumpir su conversación porque aparece la criada Cetina rezongando por lo mucho

6.- Un poco antes, Barrabás, el credenciero, hablando con él, menciona a Celestina: «Como cuentan mis vecinas, / mayormente Celestina, / diz que las viejas gallinas / hacen buena la cocina» (Torres Naharro 1994: 350). 
que tiene que trabajar. Modesta reñirá y amenazará a la muchacha, que no deja de contestarle y que se marchará más furiosa aún. Luego aparece la doncella Oripesta para decirle que la franjera o randera está esperando en la sala porque le faltó seda para una randa o encaje, y Modesta se marcha a atenderla dejando solo a su esposo, con quien se disculpa por la breve ausencia. Es entonces cuando Lepidano hablará con Perucho el hortelano echándole en cara lo mal regado que tiene el huerto después de que el vizcaíno le pregunte el porqué de su visita tan temprana ${ }^{7}$ :

$\begin{array}{ll}\text { PERUCHO: } & \text { Señor, ¿a qué sos venida } \\ & \text { a el huerta tan temprano? } \\ \text { LePIDANO: } & \text { Di, traidor, } \\ & \text { ¿por qué tienes sin temor } \\ & \text { el huerto tan mal regado? }\end{array}$

(Huete 2002: 188)

En la conversación se mencionan flores como la azucena y la clavellina, y también verduras como la berenjena, el "fadeguero» — ¿fabera?- y el perejil. Perucho no soporta las críticas de su amo, que le dice que no trabaja, y se despide discutiendo con él el tiempo que ha estado en el huerto y que debe pagarle, no sin defender su hidalguía: "No me tocáis en liñaje, / tan buena soy como a vos», y anunciando que no quiere estar más en Aragón, "mañana bien madrugada / me quiere andar a Vizcaya» (Huete 2002: 191-192). Esta decisión justifica su nueva presencia en la jornada siguiente, en la que se encuentra con el pastor Gil Lanudo y le pregunta el camino para ir a Bilbao; como el pastor, socarrón, le dirá una perogrullada ("que habés de andar / de contino hacia delante»), acabarán insultándose. Gil desprecia el linaje de Perucho, y este, al que le ha tocado en el punto flaco, lo echará al agua y lo dejará maltrecho, como se queja ("iAy, castado, / por san Juan que me ha mancado!» (Huete 2002: 206, 209).

Al hablar de las variedades lingüísticas en la Segunda Celestina, en la que aparece el habla de los negros y la de un pastor entre rústico y bucólico, ya señalé cómo en la otra comedia de Jaime de Huete, Tesorina, una negra, la esclava Margarita, habla en jerga ininteligible para los demás personajes, plagada de "xexeo", como el de Zambrán y Boruca de la comedia de Silva (Navarro Durán 2018: 387). Decía entonces que el desconocimiento de la fecha exacta de la impresión de las dos obras de Huete no permitía confirmar la posibilidad de la lectura de Feliciano de Silva porque el texto conservado (BNE, R. 4531) no tiene lugar ni año, y según Ángeles Errazu, su editora, se podría datar entre 1528 y 1535, deducción que viene de los tipos empleados en la edición (Huete 2002: XV). La nueva coincidencia

7.- Penuncio también anda por el vergel de madrugada, y, en cambio, alaba lo bien que él lo riega: «A buena fe, que hallo muy garridas estas albahaqueras y estos claveles con el rocío de esta madrugada, que no parecen estas goticas de agua, sino perlas. ¡Loado sea el que lo riega con tan buena orden!» (Gómez 2016: 373). 
con el texto de la Tercera Celestina refuerza la posible vinculación de la Segunda con las comedias de Huete y, en cualquier caso, incluso la fecha más tardía sugerida para su impresión no plantea problema para la lectura de Gómez ya que el final de la impresión de su comedia se fecha el 6 de julio de 1536.

El escritor abandona, pues, esas jergas de su modelo, de la Segunda Celestina, aunque no renuncia a que asome el habla de negros, e introduce una nueva: la de vizcaíno, con la misma finalidad: dibujar a un tipo cómico, con rasgos que se van a fosilizar, y caracterizarlo por un habla literaria que provoca también la risa. No es original, como he mostrado, pero sí tiene una voluntad de buscar otras sendas en esa continuación de la historia inacabada de la comedia de Feliciano de Silva.

\section{Uno de los dos caminos heredados: Celestina como casamentera}

En la última escena, la XL, de la Segunda Celestina, antes de despedirse, Felides va a dejar dicha su voluntad: primero a Poncia, que ha sido su verdugo - como dice- porque ha puesto fin a su encuentro amoroso con un "Señor, hora es que te vayas», le mandará "seis piezas de seda de colores para el día que se desposare público, que, si yo puedo, será antes de ocho días", y luego decide quién va a ser su casamentera: "Y la vieja Celestina quiero que concierte lo acordado de nuestro casamiento, para aprobación de su mala estimación", contando entonces lo que el lector ya sabe: el misterio de su falsa resurrección. Polandria, con razón, le ruega a Felides que no le dé tal oficio a la vieja ruin y mentirosa: "iAy, por Dios, señor, no la metas en que sea nuestra casamentera, para que, pues Dios nos ha ayuntado, no nos pueda el diablo apartar!». Pero él insiste en ello: «Señora, ¿y no sabes un proverbio que dice que lo que de Dios está, el diablo lo acarrea? Déjala; que, si de Dios está, esta lo acarreará más aína que otra persona del mundo» (Silva 2016: 346-348).

Silva ha transformado, pues, por boca de su caballero, a la alcahueta en casamentera entre personas de noble condición; no extraña al lector que Polandria se resista a aceptarla como tal porque una cosa es ser alcahueta, bien conocida por toda la ciudad, y otra servir de casamentera. La Segunda Celestina deja así en el aire esa novedosa función de la vieja puta alcahueta, y Gaspar Gómez la hace realidad en su ficción, como dice Guerry: «l'alcahueta devient marieuse dans la Tercera parte», señalando «'éloignement par rapport au modèle» del personaje (2020: 11-12). En el acto II Sigeril le resume lo sucedido la noche anterior a Pandulfo, y cuando el rufián pregunta « En qué quedaron sus amores?», Sigeril contesta: «En que Celestina será interlocutora, y se desposarán público» (Gómez 2016: 370). Pandulfo se muestra escéptico sobre la voluntad de 
"la buena vieja», pero Sigeril se lo asegura teniendo en cuenta los cien ducados que él le llevó (se lo había dicho en la escena XXX de la Segunda). Este dato corroborado va a ser esencial porque provocará la venganza del rufián (Tercera, XII), pues Celestina se negó a darle diez diciéndole que no los había recibido (Segunda, XXXIX).

Vemos que Gaspar Gómez va siguiendo el camino marcado por Feliciano de Silva; pero, como suele, introduce una modificación que va a ser significativa cuando se le añadan otras: no será Felides quien le asigne al final a Celestina el papel de casamentera, sino Polandria. Para ver la construcción de ese cambio, vamos al argumento del auto VIII:

Felides estando solo, entra Sigeril a decirle que pongan medio en hablar a Polandria; el cual le manda que llame a Celestina para que lo negocie, y Sigeril le aconseja que envíe una carta primero, y que la dará a Poncia, y según Polandria respondiere, ansí hará. Y con este acuerdo lleva Sigeril la carta. (Gómez 2016: 415)

Será, en efecto, Sigeril quien le disuade de la idea por cautela y le da dos razones: «que lo uno, evitarás las ultimadas mercedes que la haces; y lo otro, vale más saber en qué norte está la cosa por vía más secreta» (Gómez 2016: 416). Le recomienda que le escriba una carta, que él se encargará de dar a Poncia; son las diez y a él le parece hora adecuada para entregársela. Felides ya la tiene escrita porque pensaba dársela a "la mensajera», es decir, a Celestina; su contenido lo sabremos en el acto siguiente porque Polandria la lee en voz alta para que Poncia, como el lector, se entere de lo que dice. Al día siguiente Sigeril irá a recoger la respuesta de la dama, que lee también el caballero delante de su servidor, y es mucho más larga que su propia carta y acaba recordándole lo que en la Segunda Celestina había dispuesto él: "Y ansí ceso en estas últimas palabras, acordándote tengas acuerdo que, vista la presente, la buena vieja sea la medianera para renovar nuestra alegría» (Gómez 2016: 436).

Felides está en los cielos de la dicha alabando a su amada e imaginándola, y será Sigeril quien insista en que siga el consejo que ella le ha dado y lo ponga por obra; como no le precisa qué es, su señor se pondrá furioso y lo insultará. Al calmarse, le preguntará, por fin, a su criado en qué debe obedecer a su dama, y Sigeril tendrá que repetirle el final de la carta, que no quiere su amo volver a leer en su presencia:

Ella concluye con rogarte que, por que esté oculto lo pasado y se aumente en honra vuestra fama, se negocien los casamientos; y porque más astutamente lo hará Celestina que otra persona, te encomienda la tengas por encomendada enviándola luego a llamar sin alteración 
ninguna. Y en esto harás a Polandria servicio, y a ti no daño. (Gómez 2016: 438)

El caballero con razón le recuerda las veces que él le había dicho que «la buena vieja entendiese en ello", y cómo fueron las excusas de Sigeril las que frenaron su deseo. Acaba mandándole que vaya a su casa a suplicarle que venga a verle y así pueda él hablarle.

Es, pues, Polandria la que pone en marcha esa labor de Celestina como medianera en sus bodas; e insistirá ella de nuevo cuando esa embajada desemboque en el fracaso, y para verlo vamos al acto XXXI. Será Poncia quien hable con Sigeril y le dé el encargo de su ama, idea que ella también comparte porque de tal embajada no solo penden las bodas de su señora, sino también las suyas; añade además una justificación:

Y es que, conjeturando entre Polandria e yo quién entendería en estos casamientos, hallamos ser peligroso que se hablase de la parte de ella, y tocante en infamia, negociarse de partes de él; ansí discerniendo estas ocasiones, quedó concluido que Celestina vuelva a hablar a Paltrana; y para esto es menester que a la hora te envíe Felides a su casa a rogárselo, porque placerá a Dios que para el domingo esté hecho. (Gómez 2016: 577)

La precisión del domingo se relaciona con la voluntad de Felides para las bodas de Poncia manifestada a Polandria, tras su encuentro amoroso en el jardín al final de la Segunda Celestina, de que fuera antes de ocho días (Silva 2016: 347). En la Tercera hay una continua indicación sobre el paso del tiempo en horas y momentos del día, y en ello sigue también el modelo de la Thebaida ; pasarán siete días, llenos de sucesos por el doble plano de la acción: el de Felides y Polandria, que desemboca en los desposorios públicos la noche del séptimo día, y el de la alcahueta, las dos rameras y los rufianes con la sarta de castigos que aquella recibe; en el octavo día tiene lugar la muerte de Celestina porque los vecinos precisan que «Felides se desposó anoche» (Gómez 2016: 681).

Celestina va a ser la casamentera y logrará su propósito gracias a su astucia. Va a hablar a Paltrana con la excusa de pedirle una serie de untos para remediar sus males, "para ablandar y extender los niervos»" y luego le va a dar la noticia de que están tratando el casamiento de Felides con

8.- Whinnom dice: «La acción de la Comedia Thebaida transcurre en tres días y noches —y se cuentan cuidadosamente las horas- mientras la de la Segunda Celestina de Silva ocupa una semana (1988: 127).

9.- También en ello se diferencia de la Segunda Celestina, donde es la vieja la que pone remedios a los dolores de Paltrana. La condición de curandera forma parte del personaje, pero en la Tercera ella solo se aplica a sí misma los remedios que sabe; sigue siendo una excusa para entrar en casa de la dama porque le va a pedir untos la primera vez y paños «para su negra herida» la segunda (auto XXXIV). 
«una señora ansí de gran renta como de sublimado linaje, natural del reino de Aragón», y añade que había pensado en decírselo por si el caballero cuadraba para Polandria. El retrato que de él hace la alcahueta describe sus riquezas y lo sitúa en su lugar social:

Que quien con él contrata me ha afirmado ser de crecida bondad; los que le acompañan me juran ser de extremada conversación; sus vecinos y deudores publican su franqueza y liberalidad; en el pueblo, grandes y chicos cuentan y no acaban el pan que coge, el vino que encierra, el ganado que sostiene, el aceite que hace, la miel que vende, las casas que alquila, las viñas que arrienda, la casa que trae; finalmente en todas estas tierras saben la tierra que manda, y no hay rincón en Castilla do no sea notoria la generación do desciende. Y no pienses que él entiende en nada de esto, sino los mayordomos y hacedores y recaudadores que pone de su mano. (Gómez 2016: 517-519)

Paltrana se niega en redondo entonces a seguir ese camino argumentando el mucho cuidado que debe tener la mujer para tomar marido; pero lo meditará y en la segunda visita de Celestina habrá ya cambiado de opinión, le preguntará detalles sobre el supuesto compromiso de Felides; y, como la vieja le da a entender que quizás no se haya concluido aún, la dama le dice que mandará a su hermano Dardano a ver cómo está el asunto y, si el caballero está aún libre, le apuntará la posibilidad de las bodas con Polandria.

La añagaza ha surtido efecto, y como Celestina se la cuenta a Felides (auto XXXVI), él mantendrá la apariencia del compromiso no cerrado cuando Dardano vaya a verle. Y así al hablarle el caballero, amigo suyo, de su sobrina, Felides aceptará el ofrecimiento, alabando el linaje, la generosidad de Polandria, diciendo que la ha visto dos o tres veces solo y manifestando su deseo de unirse a la familia de Dardano, pero con la condición de que la joven acepte, pues no quiere un matrimonio forzado.

La invención de Celestina ha abierto un buen camino, que sabe seguir muy bien Felides fingiendo estar negociando unos desposorios inexistentes, y también sabrá hacerlo Polandria porque pondrá objeciones a la propuesta de su tío y de su madre pidiendo tiempo para conocer al caballero; pero como ambos le dicen que ya lo han negociado y que tienen que dar la respuesta antes de una hora, Polandria lo acepta en acto de obediencia. Celestina inventó el compromiso de Felides, y los dos enamorados supieron secundarla muy bien en el fingimiento y supuestamente dieron a Dardano y a Paltrana las riendas del desposorio. ¿Qué importancia tiene todo ello? Indudablemente se está creando una apariencia que tapa la relación amorosa de los enamorados previa a las bodas. Más adelante iré atando cabos. 


\section{Rufianes, rameras y el castigo de la alcahueta}

Celestina desempeña, pues, un nuevo oficio, pero no va a poder conseguir las albricias por el éxito de su empresa de casamentera porque, "yendo muy apriesa a las pedir, con el sobrado gozo, no mirando cómo va, cae de los corredores de su casa abajo, y allí fenecen sus tristes días", como dice el argumento del penúltimo acto, el XLIX (Gómez 2016: 680).

Celestina muere, por tanto, definitivamente para la literatura, y no lo hace herida por la espada de Sempronio, sino como mala imitadora de Calisto: se cae, no por una escala, sino por los corredores. Ya no se pueden asociar los versos de Jorge Manrique a ese final como podía hacerse en el texto de Rojas: «Emprendí, pues, noramala, / ya de veros por mi mal, / y en subiendo por la escala, / no sé cuál pie me resbala» ${ }^{10}$; pero sí se repite el último grito de aquella Celestina en esta: «¡Confesión!» (Gómez 2016: 681).

No solo está muerta, sino que Felides va a pagar su entierro y sepultura, como anticipan los vecinos; este es el asunto del último acto, porque el caballero, al que han informado de la muerte "desdichada de Celestina», se lo cuenta a Sigeril y describe cómo murió. Hace recuento de lo que le había dado, trescientos ducados, de lo que pensaban darle Polandria y él, más de seiscientos, y decide gastar en su entierro y misas cincuenta; pero sabiamente Sigeril le dice que son "gastos desordenados" porque todo el mundo sabía bien quién era la vieja y de qué vivía, y que bastan diez o doce ducados, aunque Felides aumentará hasta veinte la cantidad.

Pero hasta llegar a este final, Celestina ha sufrido una sucesión de percances que dibujan bien su castigo; voy a enumerarlos para poner de relieve cómo sale de todos casi indemne, a modo de personaje de entremés o de gracioso de comedia.

En el acto segundo, como he dicho, Pandulfo se entera por Sigeril de que, en efecto, Felides le dio las cuarenta doblas, y él jura vengarse de la vieja. Lo hará ayudado por su amigo Rodancho, otro rufián (acto XII); la encuentran en la calle bebiendo de un jarro con tres azumbres de vino; le dan espaldarazos y una notable cuchillada que le deja una honda herida en la pierna. Salen corriendo, pero Rodancho volverá a ver cómo ha quedado, la encontrará desmayada, la bañará en vino de cabeza a pies y le atestará el jarro en la cabeza «en lugar de coroza» (Gómez 2016: 445). Elicia y Areúsa, que irán en su busca, la encuentran en la calle desmayada, consiguen que vuelva en sí y entre las dos la llevan a su casa; lo que la vieja pide para animarse es vino y queda reposando en la cama porque les dice que ella tiene ungüentos para sanar la pierna.

10.- Son los vv. 31-34 de las coplas "Con el gran mal que me sobra», en donde también se dice "que mi bien fue todo nada / y mi gozo fue en el pozo» (v. 80), que nos llevan a las palabras de Pleberio a su mujer en su planto final: «Nuestro gozo en el pozo, nuestro bien todo es perdido» (Rojas 2000: 337). 
Se repone lo suficiente para poder ir en mula, custodiada por Sigeril y el vizcaíno Perucho, a casa de Felides a la noche siguiente. En el camino la ronda les da el alto y el alguacil Castaño (acto XVII) quiere llevarla a la cárcel "por ser la hora vedada y verla ir en mula» (Gómez 2016: 479). Mientras Perucho huye ${ }^{11}$, Celestina intenta convencer al alguacil, que está ayudado por el porquerón Falerdo, de que la libere porque va a curar el dolor de muelas de Felides ${ }^{12}$; felizmente llegará el racionero Martínez, intercede, avala a la vieja y logra que Castaño los deje seguir su camino.

En la Segunda Celestina dos despenseros, Grajales y Barrada, clientes de Elicia y de Areúsa, se pondrán al lado de Celestina, amenazada por Centurio, Traso el Cojo y Tripa en brazo. En cambio, ahora Barrada la azotará con una tripa de vaca llena de excrementos y le robará los cincuenta ducados que le ha dado Felides; lo hará como venganza porque ha ido a su casa y ha oído como Albacín está con Elicia, y promete cobrarse los cuatro ducados que le dio a la vieja en la escena XXXIV de la Segunda Celestina ("Ves aquí cuatro ducados para una saya, para paga y señal» Silva 2016: 283). La deja en la calle «enmerdada» y lamentándose de su desastrada y malaventurada vida.

Gaspar Gómez castiga a la vieja del modo que indican los apodos de los dos rufianes amigos de Centurio: hace que la dejen coja como lo es Traso el cojo, y que la golpee Barrada con una tripa llena de excrementos siguiendo el nombre de Tripa en brazo. Pero aún queda lo peor en este calvario de la alcahueta porque también Albacín se vengará de ella dándole una cuchillada en la cara (precisamente se la conocía en la obra de Rojas por tener una) y se lleva luego de su casa a Elicia (acto XXXVII).

Después Recuajo y Grajales, al ver que está Areúsa en casa de Celestina con Bravonel, desquician la puerta de la casa y los atacan: le cortan un brazo al rufián, que huye por los tejados, y matan a la ramera (acto $\mathrm{XL})$. Al volver a su casa la vieja, el corregidor oye la barahúnda, manda que la apresen y la castiguen por alcahueta: el pregonero la va azotando por las calles mientras vocea que "por encubridora y alcahueta» la mandan azotar y emplumar públicamente; le atiesta la coroza, la empluma, la sube a la escalera, la ata y allá la deja al sol para que los muchachos se burlen de ella; acaba el acto XLI anunciando que el alguacil y el verdugo llegan a bajarla de allá.

11.- En la Segunda Celestina, IV cena, mientras los criados de Felides están dando música a Quincia porque Pandulfo les ha pedido a Sigeril, Canarín, Corniel y Barañón que le acompañen a dársela a la moza a las once de la noche, Sigeril oye ruido de armas, y Pandulfo no espera a saber quiénes son y huye; será la ronda con el alguacil, pero cuando aquel le dice de quiénes son criados, solo le pide que no alboroten más y que se vayan. La escena es paralela, pero muy distinta en la Tercera; lo único que se mantiene es la huida del cobarde mozo de mulas, sea Pandulfo o sea Perucho.

12.- Gómez retoma el asunto del dolor de muelas del acto IV de La Celestina, como le dice la alcahueta a Melibea: «Una oración, señora, que le dijeron que sabías de Santa Polonia para el dolor de las muelas» (Rojas, 2000: 129). 
Tras el castigo público a manos de los hombres, no le queda más que la muerte ya descrita: su prisa para conseguir el dinero que le va a dar Felides por haber llegado a buen puerto las bodas que ella negoció le lleva a la caída que la mata. Aunque había sido afrentada públicamente, como se dice a sí misma en su último monólogo, ya no tenía a nadie que amenazase su futura ganancia: "Y veo que no tengo agora a Barrada que me afrente, ni Bravonel que me robe, ni Albacín que me hiera, ni Elicia que hurte, ni Areúsa que esconda, ni gato que golosmee, ni perro que me ladre. En conclusión, cuanto me dieren y lo que más ganaré, todo lo gozaré yo en comer y beber y echar sobre mí» (Gómez 2016: 680-681).

Ese resumen de vida desemboca no en lo que imagina Celestina, sino en la muerte. La alcahueta hecha casamentera sale tan ligera de su casa, azuzada por la ganancia que le espera, que da un último mal paso para dejar de existir y lo hace en esa Tercera Celestina, en donde la figura ha perdido todo su empaque para convertirse casi en un pelele, golpeado, acuchillado, castigado, pero aparentemente incólume antes de despeñarse por los corredores de su casa.

En el acto XIX la retrató con trazos expresionistas Areúsa en conversación con Albacín, que la llama "la puta hechicera», y con Elicia:

Yo te prometo, más años tiene a cuestas que dos los más antiguos del pueblo. Y esto sin jurarlo se vee en ella por experiencia; que tiene ya los ojos hundidos, las narices húmidas, los cabellos blancos, el oír perdido, la lengua torpe, los dientes caídos, la cara arrugada, los pies hinchados, los pechos ahogados. En conclusión, es mi pensar que, si la sepoltura hablase, como acá será suya, la compelería por justicia a que fuese a poblar su casa. (Gómez 2016: 497)

Así fue, pero ella, Areúsa, la antecedió en ese camino, porque como le había dicho Celestina a Poncia en la Segunda Celestina: «¿Y no sabes, mal pecado, que tan presto se va el cordero como el carnero?» (Silva 2016: 152).

Albacín juró vengarse de la vieja en ese momento de la conversación con Elicia: «iMas no me llamaría yo hijo de mi padre si no me pagase la embaucadora las quistiones que contigo tiene juntamente con el enojo que me da!» (Gómez 2016: 497). Y aunque entonces ella le pidió que no lo hiciera, en el acto XXV le recuerda lo que él le dijo: «que no es más de que me vengues de la vieja», y Albacín se lo promete: "yo te doy mi fe de castigarla antes de tres días, de manera que hayas placer, y te saque de su casa con tu honra» (Gómez 2016: 540). Elicia se marchará con el joven paje del infante, pero no le espera mejor futuro que a Quincia, aunque él le diga "que soy hombre para te mantener a mi honra y tuya muy ocultamente» (Gómez 2016: 612). 
No solamente siguen actuando en la Tercera Celestina Pandulfo, Barrada y Albacín, mucho más arrufianados, sino que se suman a ellos el rufián Rodancho, amigo de Pandulfo, y Bravonel, amigo de Grajales. Barrada y Grajales habían ido en busca de Centurio y sus compinches, que habían dado un repiquete de broquel a Celestina, en la Segunda Celestina; pero en esta continuación los dos son atacantes suyos, primero Barrada (XXVI), y luego Grajales ayudado por Recuajo, como he dicho, aunque aquí el enemigo de Grajales es su antes amigo Bravonel: así se retrata bien el ambiente de esos rufianes en sus disputas por una ramera, y con sus ataques entre ellos mismos. Bravonel además tiene una iza, Ancona, a cuya casa acude con el brazo cortado y, como si nada le pasara, se pelea con ella; le pide lo ganado y, cuando ella le da los diez reales que tiene, quiere una perdiz, que ella le niega, y, por ello, la golpea; tiene que intervenir otra prostituta, Solercia, que los deja ya apaciguados y se marcha diciendo «que está un mancebo a mi puerta» (Gómez 2016: 652). Al comienzo, en el acto VII, se había contado otra riña de un rufián con su moza: era Pandulfo con Quincia, que se negaba a darle la saya de grana que había sido de Polandria y unos corales; en este caso fue el rufián Rodancho quien los puso en paz.

En la Segunda Celestina hay una pelea entre la alcahueta y Elicia con la iza de Pandulfo, Palana (escena XXII), que había acudido a su casa convencida de que allí estaba el rufián; y como le dan con el chapín y la rueca y le tiran de los pelos - y se quedan con ellos porque eran postizos-, y ella acude a la justicia, Celestina y Elicia acaban retraídas en el monasterio de Santa Clara; en cambio, en la Tercera, el enfrentamiento es entre los rufianes, Grajales y Recuajo, que tras matar a Areúsa, también van a retraerse (XL). No son ya peleas de rameras, sino un asesinato cometido por un rufián, y de nuevo asoma la rectificación de Gómez a su modelo porque no parece motivo de retraimiento una riña de prostitutas sin consecuencias graves.

El mundo rufianesco que rodea a la alcahueta se enriquece, pues, con nuevos personajes, y la acción entre ellos y Elicia, Areúsa y Celestina se intensifica. Como consecuencia de esto, la mala vieja sufre una sarta de castigos: de los rufianes que quieren a las dos prostitutas que tutela o su dinero, y de la propia justicia. Ella parece salir indemne de todo ello a pesar de las heridas que va recibiendo, de tal forma que, al cantar victoria al final con la buena nueva de los desposorios de Felides y Polandria, muere al caerse sin que nadie la empuje. Es el castigo divino a su vida; a ello hay que añadir que Areúsa está muerta y Elicia se ha fugado con Albacín. 


\section{Personas generosas y de alto linaje: Felides y Polandria}

Como le dice el escudero Ervión a su señor Felides «porque a las personas generosas y de alto linaje, y de suntuosa casa y de gran renta, y que esperan como esperas ser señor de vasallos, más veces han de hallar sus súbditos su cara alegre que sus pensamientos tristes» (Gómez 2016: 486). Y ese personaje, que solo aparece en el acto XVIII y hereda rasgos del Menedemo de la Thebaida, seguirá aconsejando a su señor para que guarde el decoro de su condición: «No des tanta prisa a tu apresurado deseo, que apocas tu persona y desminuyes tu fama en hacerte siervo de tu criado y de la que no merece serlo» (Gómez 2016: 487). No le va a hacer caso Felides, pero su comportamiento en esta Tercera parte es mucho más acorde a su condición; antes le había pedido a su consejero que le buscara en la recámara «el Libro de bien amar» y justificó su petición diciendo "porque pasaré tiempo un rato con él; que es tan sutil que no solamente aliviará mi pasión, mas avivará el ingenio, que tan turbado tengo» (Gómez 2016: 485).

Gaspar Gómez distancia clarísimamente los estratos sociales: rufianes, prostitutas y la alcahueta, el intermedio de los criados y el de los señores. Y lo hace desde el comienzo de su Tragicomedia hasta el final.

Felides no irá en la Tercera a casa de Celestina como lo hizo en la Segunda (escena XVII), sino que mandará a Sigeril con Perucho a que vayan con una mula a buscarla y la lleven a su casa puesto que ella no puede ir por su pie tras el ataque de Pandulfo, y también irá la segunda vez un servidor suyo, en este caso el cobarde Perucho; en la obra de Silva el propio Felides va además al monasterio de Santa Clara, donde están retraídas Celestina y Elicia para tranquilizarlas diciéndoles que pueden volver a su casa porque él va a mediar. En la Tercera, él se entera del encuentro de la alcahueta y de sus criados con el alguacil de la ronda, pero no tiene necesidad de intervenir porque Martínez el racionero soluciona el problema. Castigada públicamente por orden del corregidor, al sol en mitad de la plaza, uno de los muchachos que se burlan de ella le pregunta: «Tu señor Felides ¿por qué causa no te favoreció?»; entonces ella replica que la llevaron desde su casa al castigo, y añade: "Y aun agora he sabido que fue esta mañana a caza, ique otramente no estuviera la sinventura de Celestina a este sol!» (Gómez 2016: 636-637). Felizmente el caballero está lejos del escenario, cazando como le corresponde a su condición, y no tiene que intervenir en este vergonzoso asunto. Precisamente Sigeril en el acto XXXI le había hablado a Poncia de la cacería de su señor como causa de su temprana presencia ante la casa de Paltrana: «Yo te certifico que la principal causa que tuve para salir tan temprano fue ir a casa del marichal a decirle de partes de mi señor Felides que se aparejase para de aquí a media hora ir a caza, porque a las seis han de estar en el monte» (Gómez 2016: 576).

El Felides de Gómez guarda distancias con la intermediaria, y además es Polandria la que le dice a él dos veces que vaya a pedirle que desem- 
peñe el papel de mediadora entre él y su madre, como ya he indicado. Y la mención del marichal como amigo suyo no es la única porque en la invención de Celestina de los supuestos desposorios de Felides que se estaban negociando, la pretensora - con considerable dote- era su hija.

Ese marichal, compañero de cacerías de Felides, da entidad social al caballero, y también le aumentan su importancia los muchos servidores que tiene; además desaparece de su casa Pandulfo, tan rufián que se lleva consigo a la criada Quincia de Polandria, que en principio iba a ser solo la puerta de entrada a la casa. Ambos desmerecen a sus señores y pasan a incrementar el ámbito del bajo mundo de rufianes y rameras; la misma pelea que tienen, apaciguada por Rodancho, nos recuerda la de Pandulfo y Palana de la Segunda. El vizcaíno Perucho, mozo de mulas de Felides, sustituye a Pandulfo y se asemeja a él por su cobardía, pero las burlas que le hacen Elicia y Areúsa subrayan su condición de rústico (le llaman borrico, bestia, burro, asno), aunque presuma de su linaje - como corresponde al personaje-y no le falte atrevimiento.

Sigeril sigue al pie de su amo, pero más en su papel: le miente porque le dice que ha ido a ver a Polandria y no lo ha hecho; aunque es cierto que siempre está junto a Felides y le aconseja cuerdamente hasta el final. Cuando le dice a su señor que quiere irse un mes a su tierra a buscar lo que le corresponde de herencia para poder casarse con Poncia, se pone de manifiesto la gran generosidad del caballero porque considera que el dinero que la joven le exige corre a su cargo: «y pésame que tan incrédula me tengas la fe en pasarte por pensamiento que donde yo estoy has menester cobrar tu hacienda para te casar. Y por que no digas otro día semejantes palabras, toma este libramiento de trecientos ducados que en mi cambio te mando dar para el día que te casares» (Gómez 2016: 388). La generosidad y el dinero que tiene Felides se muestra con su criado, con Poncia, con Celestina, a quien le da dinero y regalos valiosos, y también le manda a Sigeril que lleve abundante comida a casa de la alcahueta ${ }^{13}$.

Gómez no solo mantiene a dos criados de la Segunda, a Corniel y a Canarín, que cantará en la música que dan a Polandria (y no a Quincia, serenata fuera de razón) y en los desposorios de los dos protagonistas, sino que también le da un pequeño papel a Calverino, mozo de espue-

13.- En la Segunda Celestina hay dos comidas en casa de la alcahueta, pero son distintas porque quien lleva dos pares de perdices en la primera (escena XXIX) es Grajales, despensero del arcediano, y en la segunda es Buzarco, el mozo de Grajales, quien dice que su señor y Barrada, despensero del maesescuela, les envían «estos capones y estas perdices con este cangilón de vino de Morviedro» (Silva 2016: 278), y ellos serán los comensales junto a la alcahueta y las dos rameras. La generosidad de Felides es muy superior; basta ver la enumeración de los manjares y vino con los que ha cargado Sigeril hasta la casa de Celestina, y como él le dice encareciendo la liberalidad de su señor: «ni sabe lo que traje ni lo preguntará; mas de que me mandó que entrase en la despensa y botillería y te trajese muy cumplidamente lo que fuese mi voluntad de todo lo que hallase» (Gómez 2016: 588). El episodio de la comida en casa de la alcahueta arranca del acto IX de La Celestina original. 
las de Felides (auto XV), y al moralista Ervión, su escudero (auto XVIII). Corniel, el paje, será quien le contará a Sigeril que tienen «la mejor y más copiosa librea que hasta hoy se ha visto", y le precisará que quienes la llevarán serán lacayos y pajes: "Los lacayos son veinte y cuatro, y los pajes le han ofrecido tantos a sus hijos que mandó cortar para treinta", y ante el asombro y la admiración de Sigeril, le dice que entre a ver a su señor "que leyendo está» (Gómez 2016: 384, 386, 387). Este acto cuarto es el que marca las diferencias claramente entre el caballero Felides y el personaje Felides de Feliciano de Silva, y lo hace con la descripción de las libreas que ha encargado para sus servidores.

Como dice Corniel a Sigeril, hay un batallón de oficiales trabajando en ellas: "según los sastres, calceteros, jubeteros, bordadores, zapateros se dan la prisa, anque hoy se cortaron a medio día, de mañana a hora de misa estaremos vestidos». Y ante la incredulidad del paje — que no hace tanto salió de casa y no sabe nada-, él describirá, ante su petición, los colores de las libreas:

Las colores de nuestra librea son sayetes hechos a la tudesca, de grana colorada, que de ello a carmesí no hay diferencia, con unas fajas de terciopelo verde de tres pelos tan anchos como cuatro dedos, con unas pestañas angostas de damasco blanco. Y las mangas izquierdas son de terciopelo verde con dos sutiles corazones en cada manga de carmesí, que casi están juntos con una saeta que entra por el uno y sale por el otro. (Gómez 2016: 385)

Y seguirá con las calzas, los jubones, las gorras, las capas... Sigeril pasa del asombro ante lo que oye a la desaprobación por el exhibicionismo de las galas de Felides. Y Corniel lo frenará recordándole «el generoso linaje de do desciende", el tesoro que tiene heredado de su padre y la renta de que goza. Irá el paje a ver a su señor, y será entonces cuando le dé la citada carta de libranza para su cambio, y luego le explicará el significado de los colores de la librea: «Los sayos y capas son de grana, a significanza de la extraña e increíble alegría que poseo; por guarnición llevan fajas verdes con pestañas blancas, queriendo demostrar la esperanza de la gloria venidera» (Gómez 2016: 389). Le precisará que a él le ha hecho hacer el sayo de terciopelo verde y así todo lo demás porque su situación no es la del gozo sino la de la esperanza.

Menéndez Pelayo hizo una total descalificación de la Tercera Celestina diciendo que "la fábula es insulsa y deslavazada, el estilo confuso, incorrecto y a veces bárbaro" y afirmó que el autor «apenas pone nada de su cosecha»; en cambio, a su parecer sí merecía recordarse «la descripción que el paje Corniel hace de los trajes y atavíos preparados para la boda de Felides» (1943: 83, 86). Esa exhibición pública de la cortesanía de Felides tiene su origen también en la Comedia Thebaida, donde Berintho le manda a 
Menedemo que dé «a esos pajes y a esos mozos de espuelas las libreas de carmesí pelo que les estaban hechas para el recibimiento del César»; sumará a ello la orden de que "algunos continos de casa justen la primera fiesta que venga", que se corran seis toros en la plaza y luego precisa generosos regalos para Franquila, Claudia y Veturia; a la intermediaria, Franquila, además de piezas de seda, dice que le envíen "seis marcos de plata labrada" (1968: 232), y asociamos ese regalo al que Felides le hace a Celestina de un par de jarros de plata y una pieza de contray (Gómez 2016: 608).

Precisamente para que los criados tengan relaciones amorosas en el vergel igual que los señores, y Poncia no pueda, pues, hacer sus sermones y moralidades -impropios de su condición-, tras el primer encuentro en el vergel, que se queda solo en música y palabras por el peligro que supone para la fama de la dama el conocimiento que el hortelano y la negra tienen de la relación amorosa en el jardín en la escena final de la Segunda Celestina, vendrá la segunda cita en el espacio textual de la Tercera. Será Polandria quien convoque a ella a Felides, pero lo hará a través de una carta que no se lee en el texto y que, por tanto, tampoco han visto ni oído ni Poncia ni Sigeril: la joven ruega a su amado que la rompa tras leerla, y así lo hace él. Frente a la primera carta de Felides, que lee Polandria en presencia de Poncia, y la de ella, que leerá el caballero en voz alta ante su criado, Gaspar Gómez ofrece la variante de esta tercera, que sirve de cita, pero calladamente.

En el auto XXVIII acudirán Felides y Sigeril al vergel muy ocultamente para que nadie los oiga, entran por la puerta falsa, que está entreabierta (no tienen, pues, que arriesgarse escalando), Polandria recibe al caballero, y Poncia sigue defendiendo su honra, sobre todo mencionando la pobreza de Sigeril; pero Felides cortará de raíz sus discursos dándole cien ducados y prometiéndole otros doscientos el día en que se desposará con Sigeril, coincidiendo con sus esponsales, que anuncia van a ser antes de tres días. Con el dinero, no hay más palabras, sino hechos: los mismos en los criados que en los señores, solo que el texto está para ofrecer al lector un primer plano de la relación entre Sigeril y Poncia; los señores "están detrás de aquel manzano holgando como hemos holgado» (Gómez 2016: 561), como le dice el criado a ella.

Curiosamente la frase descortés que le contesta Calisto a Melibea cuando ella se resiste a que la desnude: «Señora, el que quiere comer el ave, quita primero las plumas» (Rojas 2000: 321), que es imitación de Plauto ${ }^{14}$, está en boca de Sigeril en parecida circunstancia; al «iNo me descubijes!» de Poncia, el criado contesta: "Calla, bien de mi vida, que no hay ave que se coma si primero no se le quita la pluma» (Gómez 2016: 561). Gómez

14.- De su comedia Curculio, uno de cuyos personajes es la vieja borracha Leena, que se considera precedente de la Celestina; en ella el esclavo Palinuro le dice a su señor Fédromo: «El que quiere comerse una nuez, primero rompe la cáscara. El que quiere acostarse con su amiga, despeja el camino con besos» (Plauto 1998: 520). 
corrije al propio Rojas y pone en boca de quien debe tal frase para que sea decorosa: en la del criado Sigeril, y no en la del caballero Calisto.

El dinero, pues, acalla discursos morales, y quienes lo tienen son los señores. La condición que caracterizaba a los dos criados, «ella bachillera y él licenciado", queda ya en un segundo plano. Y ese dinero seguirá manando de los señores hacia esa pareja de sirvientes privilegiados (a él lo asciende a camarero Felides, y ella es la única doncella de Polandria y su confidente): en el auto XLVII, tras «los conciertos de Sigeril y Poncia», Felides le da doscientos ducados para su dote, Paltrana otros cien y Dardano cincuenta; y también ellos creen que han tenido un papel decisivo en concertar las bodas de los criados como si la idea hubiera sido suya, y no se conocieran antes los dos muy bien. Así se representa una pequeña farsa en ese acto, en donde oímos primero a Polandria decir sobre su concertado matrimonio con Felides: «Por cierto, señora, yo conozco que Dios tuvo por bien de me le escoger. Empero, pues tú le nombraste y mi señor tío Dardano lo concertó, yo digo que acepto tu mandato en le obedecer»; y poco después a Poncia, que se ríe cuando le dice su señora Paltrana que la quieren desposar con Sigeril, «este mancebo que tiene mi hijo por su camarero", y justifica su risa diciendo "de que no pude hacer menos en ver la joya que me habíades escogido"; y la señora la reprende: «Rapaza, ¿por qué eres tan malcriada que, sin verle ni contratarle en tu vida, dices lo que se antoja en nuestra presencia» (Gómez 2016: 665, 669). Triunfa, pues, la apariencia: ninguna de las dos parejas se conocía antes (y el término "conocer» tiene aquí la acepción bíblica).

En el auto XXXIX se inician las conversaciones entre las dos partes para los desposorios entre Felides y Polandria - Celestina se queda sin papel-. Es Dardano, el hermano de Paltrana, quien actúa de intermediario ${ }^{15}$, y luego se dedicarán cuatro autos más (42, 43, 45 y 47) como preparación a los solemnes desposorios de ambos en casa de Paltrana, que van a ser oficiados por el arcediano Antenor, sobrino de la dama (48). Como Polandria solo tiene madre, Gómez fortalece su familia con esos dignísimos tío y primo, frente a un solitario Felides, que no necesita parientes por la riqueza y poder que tiene en la ciudad; son ellos además los que deben negociar la boda con el caballero, como sucede ya en la Thebaida.

Felides es un caballero rico y noble, tiene muchos sirvientes y vive en una gran casa. Así se lo dice la alcahueta en su segunda visita; se encuentra a

15.- De nuevo el modelo es la Comedia Thebaida, donde son los tíos de Cantaflua, Floribundo y Archano, los que al ver las ricas libreas de los criados de Berintho, "temiéndose de lo que podría ser», hablan con la joven, y al ver que está decidida a desposarse con él, "concertaron entre ellos que sería bien que pusiesen algunos caballeros de la ciudad, amigos suyos, para que te hablen y el casamiento se concertase, y con esta determinación se partieron de Cantaflua muy conformes y muy contentos» (1968: 248). En la Segunda es Celestina quien tiene un primo, Barbanteso, que va a reprehender a la vieja cuando tanto tiene que callar como le echa en cara ella; su presencia no tiene papel alguno en la comedia, mientras sí lo tendrán tío y primo de Polandria en la Tercera. 
Felides en la calle con Sigeril, es la una, hace un sol fuerte, y los tres entran en la casa; le pide el caballero a su criado que ponga unas sillas en la sala de abajo, y Celestina, ante su comentario de que la casa está fresca, dice: «Señor, como, ¡loores a Dios!, tienes muchos criados, mientras uno barre, otro riega y otro trae estas espadañas», y Felides le da el mérito a «un mozo muy liberal que recibí anoche para cosas semejantes» (Gómez 2016: 529).

Lo mismo sucede con la casa de Paltrana porque, además de su gran vergel, cuidado por el hortelano Penuncio, se menciona la sala de su casa; y se habla de la negra Boruga, esclava mora a su servicio (heredada de la Segunda Celestina), pero también de dos pajes: Guzmanico y Frunces. Los desposorios se harán en su casa, adonde acude Felides con doce pajes y doce mozos de espuelas, vestidos con libreas — no se han podido acabar las libreas para los demás.

Los desposará el arcediano Antenor y después tocarán los ministriles sus trompetas, chirimías y sacabuches, y cuando cante Canarín, tañerán primero arpas, laúdes y vihuelas, y luego solo vihuelas de arco y rabeles. La música se acaba con la invitación de Dardano de entrar en otra sala donde están puestas las mesas para cenar.

La separación entre ese mundo cortesano y el de los rufianes y rameras es, pues, marcadísimo. No hay mezcla ya ni confusión posible. Los límites están claramente trazados con la exhibición de las libreas, con el simbolismo de los colores; es el ámbito de la Questión de amor (Valencia, 1513) el que asoma, siguiendo algunos pasos que ya trazó el autor de la Comedia Thebaida.

No hay más que contrastar el final de la Segunda Celestina con el de la Tercera: se cierra con un largo parlamento moralizante de la honesta Poncia a su señora, que comienza con la dura reprehensión: «Y tú, señora, ¿para qué haces cosa que no quieres que se sepa, pues sabes que no hay cosa encubierta que no se descubra?», aunque luego lo aminora al afirmar que no ofendió a Dios puesto que Felides era su esposo por el matrimonio secreto. En cambio, el auto L, el último de la Tercera — que se concluye de forma más redonda con 50 actos y no con 40-, tiene como personajes a Felides y a Sigeril, señor y camarero, y quedan muy claros sus papeles porque cada uno dice lo que le pertenece. Felides se muestra generoso y buen cristiano, y Sigeril, obediente servidor:

Felides: Por tu vida, que cumplas con mi voluntad en que tomes estos veinte ducados y se gasten, pues es harto poco; y tengas cuidado de hacer que la entierren luego, y que la sepoltura sea en buen lugar de la iglesia.

SigERIL: Pierde cuidado; que todo se hará como mandas y lo más breve y mejor que ser pudiere.

(Gómez 2016: 686) 
Es la última imagen que nos da la obra: la del rico y generoso caballero Felides, felizmente casado ya con su amada Polandria, pagando el entierro de Celestina, que ha ido a la sepultura empujada por su inagotable avaricia y llevada por su propio pie.

Todo está ya bien acabado: Gaspar Gómez ha seguido el guion de Feliciano de Silva, pero ha devuelto el decoro a los personajes. Los criados actúan como criados, y los señores como señores; el mundo de los rufianes y prostitutas no se mezcla con el de estos. Lo sucedido en el vergel entre Felides y Polandria pasó ya en la Segunda Celestina; en la repetición nada de ello se detalla, y el lector se da cuenta de que es solo una excusa para que Sigeril y Poncia los imiten, vencida la resistencia de la doncella por el dinero que el caballero le ha dado. Como solo lo saben los cuatro protagonistas ${ }^{16}$, y los desposorios públicos han sancionado ya los secretos, no hay deshonra alguna en Polandria ni atrevimiento excesivo en Felides; han sabido los dos fingir muy bien delante de los familiares: de Dardano, en el caso del caballero, y de este y su hermana Paltrana, en el de Polandria, que se resiste hábilmente a dar el sí al desposorio. El disimulo es un arte del que ambos dan una excelente lección, y que sabrán imitar sus fieles criados, desmintiendo así las palabras de Poncia en la Segunda: «no hay cosa encubierta que no se descubra».

Las libreas con el significado de sus colores son la mejor exhibición de cómo el relato prostibulario puede mezclarse con el cortesano siempre que se ponga a los personajes en el sitio que les corresponde, guardando el decoro de su condición. 


\section{Bibliografía}

BARRICK, Mac E. (1973), "Introduction», Gaspar Gómez de Toledo, Tercera parte de la tragicomedia de Celestina, Philadelphia, University of Pennsylvania Press, pp. 1-71.

CANET VALLÉs, José Luis (1993), De la comedia humanística al teatro representable (Égloga de la tragicomedia de Calisto y Melibea, Penitencia de amor, Comedia Thebayda, Comedia Hipólita, Comedia Serafina), UNED, Universidad de Sevilla, Universitat de València.

Gómez de Toledo, Gaspar (1973), Tercera parte de la Tragicomedia de Celestina, ed. de Mac E. Barrick, Philadelphia, Univesity of Pennsylvania Press.

- (2016), Tercera parte de la tragicomedia de Celestina, en Segundas Celestinas, ed. de Rosa Navarro Durán, Madrid, Biblioteca Castro.

Guerry, François-Xavier (2020), «Du personnage Celestina au type célestinesque. Stéréotypie et innovations dans un cycle littéraire du Siècle d'or (1499-1570)», Crisol, 10, pp. 1-15.

Heugas, Pierre (1973), "La Célestine» et sa descendance directe, Bordeaux, Éditions Bière, Bibliothèque de l'École des Hautes Études Hispaniques, XLIV.

Huete, Jaime de (2002), Tesorina. Vidriana, ed. de Ángeles Errazu, Zaragoza, Prensas Universitarias de Zaragoza, Instituto de Estudios Altoaragoneses.

La comedia Thebaida (1968), ed. by G. D. Trotter and Keith Whinnom, London, Tamesis Books.

- (2003), ed. de José Luis Canet Vallés, Salamanca, Ediciones Universidad de Salamanca.

Manrioue, Jorge (1993), Poesía, ed. de Vicente Beltrán, Barcelona, Crítica. Menéndez Pelayo, Marcelino (1943), Orígenes de la novela, IV, ed. de E. Sánchez Reyes, Santander, Aldus, CSIC.

Navarro DurÁn, Rosa (2018), "Caminos abiertos en una comedia transgresora: La Segunda Celestina de Feliciano de Silva», Celestinesca, 42, pp. 375-394.

Piccolomini, Eneas Silvio (1907), Historia de dos amantes, traducción al castellano (2a impresión, Sevilla, Jacobo Cronberger, 1512), ed. de R. Foulché-Delbosc, Barcelona, l'Avenç.

Plauto (1998), Curculio en Comedias, I, ed. y trad. de José Román Bravo, Madrid, Cátedra.

Question de amor (1995), estudio crítico, edición y notas de Carla Perugini, Salamanca, Ediciones Universidad de Salamanca. 
RojAS, Fernando de (y «antiguo autor») (2000), La Celestina. Ed. de Francisco Rico et al., Barcelona, Crítica.

Silva, Feliciano de (2016), Segunda comedia de Celestina, en Segundas Celestinas, ed. de Rosa Navarro Durán, Madrid, Biblioteca Castro.

Torres Naharro, Bartolomé de (1994), Obra completa, ed. de Miguel Ángel Pérez Priego, Madrid, Biblioteca Castro.

WhinNom, Keith (1988), "El género celestinesco: origen y desarrollo", en $V$ Academia literaria renacentista. Literatura en la época del Emperador, ed. Víctor García de la Concha, Salamanca, Universidad de Salamanca, pp. 119-130. 